\title{
Enabling Wearable Pulse Transit Time-Based Blood Pressure Estimation for Medically Underserved Areas and Health Equity: Comprehensive Evaluation Study
}

Venu Ganti ${ }^{1}$, BS; Andrew M Carek ${ }^{1}$, PhD; Hewon Jung ${ }^{1}$, MS; Adith V Srivatsa ${ }^{2}$; Deborah Cherry ${ }^{3}$, BBA; Levather Neicey Johnson ${ }^{3}$, BSN, RN; Omer T Inan ${ }^{1,2}$, PhD

\footnotetext{
${ }^{1}$ School of Electrical and Computer Engineering, Georgia Institute of Technology, Atlanta, GA, United States

${ }^{2}$ The Wallace H. Coulter Department of Biomedical Engineering, Georgia Institute of Technology, Atlanta, GA, United States

${ }^{3}$ VSNS, Inc, Atlanta, GA, United States
}

\section{Corresponding Author:}

Venu Ganti, BS

School of Electrical and Computer Engineering

Georgia Institute of Technology

85 5th St NW

Atlanta, GA, 30308

United States

Phone: 12406434250

Email:vganti6@gatech.edu

\section{Abstract}

Background: Noninvasive and cuffless approaches to monitor blood pressure (BP), in light of their convenience and accuracy, have paved the way toward remote screening and management of hypertension. However, existing noninvasive methodologies, which operate on mechanical, electrical, and optical sensing modalities, have not been thoroughly evaluated in demographically and racially diverse populations. Thus, the potential accuracy of these technologies in populations where they could have the greatest impact has not been sufficiently addressed. This presents challenges in clinical translation due to concerns about perpetuating existing health disparities.

Objective: In this paper, we aim to present findings on the feasibility of a cuffless, wrist-worn, pulse transit time (PTT)-based device for monitoring BP in a diverse population.

Methods: We recruited a diverse population through a collaborative effort with a nonprofit organization working with medically underserved areas in Georgia. We used our custom, multimodal, wrist-worn device to measure the PTT through seismocardiography, as the proximal timing reference, and photoplethysmography, as the distal timing reference. In addition, we created a novel data-driven beat-selection algorithm to reduce noise and improve the robustness of the method. We compared the wearable PTT measurements with those from a finger-cuff continuous BP device over the course of several perturbations used to modulate BP.

Results: Our PTT-based wrist-worn device accurately monitored diastolic blood pressure (DBP) and mean arterial pressure (MAP) in a diverse population ( $\mathrm{N}=44$ participants) with a mean absolute difference of $2.90 \mathrm{~mm} \mathrm{Hg}$ and $3.39 \mathrm{~mm} \mathrm{Hg}$ for DBP and MAP, respectively, after calibration. Meanwhile, the mean absolute difference of our systolic BP estimation was $5.36 \mathrm{~mm}$ $\mathrm{Hg}$, a grade B classification based on the Institute for Electronics and Electrical Engineers standard. We have further demonstrated the ability of our device to capture the commonly observed demographic differences in underlying arterial stiffness.

Conclusions: Accurate DBP and MAP estimation, along with grade B systolic BP estimation, using a convenient wearable device can empower users and facilitate remote BP monitoring in medically underserved areas, thus providing widespread hypertension screening and management for health equity.

(JMIR Mhealth Uhealth 2021;9(8):e27466) doi: 10.2196/27466

\section{KEYWORDS}

wearable sensing; pulse transit time; cuffless blood pressure; noninvasive blood pressure estimation; health equity; mobile phone 


\section{Introduction}

\section{Background}

Current clinical practice regarding hypertension management and control hinges on the century-old approach of obtaining infrequent cuff-based measurements of blood pressure (BP) in clinical settings. This paradigm of the measurement being anchored to the clinical setting and requiring persons to proactively visit a medical professional to determine their hypertensive status is costly-due to the time and money spent [1] — and considered ineffective-due to the infrequency and error (ie, white coat hypertension) of office BP measurements $[2,3]$. Hence, we observed remarkable disparities in hypertension detection, treatment, and control across socioeconomic status and race, with populations lacking access to regular office visits and care, having nearly half the awareness of their existing hypertensive status, and enduring up to triple the rates of subsequent cardiac events [4,5]. Technologies that enable frequent, reliable, and accurate measurements of $\mathrm{BP}$ in ambulatory settings promise to reduce the global burden of hypertension and offer an opportunity to advance health equity [6]. Leveraging the ubiquity of smartphones and digital health technologies equipped with highly sensitive, miniaturized sensors is essential for the remote monitoring of BP [7].

Existing wearable devices that incorporate noninvasive BP methodologies offer an affordable and efficient means of tracking out-of-office BP [8]. Unfortunately, they commonly use uncomfortable techniques (ie, oscillometry and tonometry) that demand imparting forces on blood vessels to achieve accurate measurements [9-11]. These inconveniences fail to empower users to take control of their health, posing a significant challenge to the widespread routine monitoring of BP. Instead, strategies that compute the pulse transit time (PTT), a measure of arterial stiffness, present a convenient alternative for BP estimation [12].

The PTT, the time the pressure wave propagates along the length of the arterial tree, is a cuffless surrogate for BP and can be acquired noninvasively [12]. In practice, the acquisition of noninvasive PTT requires a combination of sensors-typically an accelerometer, force sensor, light-emitting diode (LED) and photodiode, electrode, or ultrasonic transceiver-placed proximally and distally along the arterial tree and computed from fiducial points in the captured seismocardiogram (SCG), ballistocardiogram, photoplethysmogram (PPG), impedance cardiogram, impedance plethysmogram, or arterial blood pressure $(\mathrm{ABP})$ waveform [13,14]. Despite their inherent convenience, these sensing modalities are naturally of concern when used in populations with intrinsic mechanical, optical, and electrical barriers, stemming from higher melanin levels and body fat percentages.

To the best of our knowledge, noninvasive PTT-based BP estimation has yet to be examined in a diverse population-a gap in our scientific understanding that presents a formidable obstacle to its adoption. Specifically, some medically underserved areas (MUAs), which stand to benefit the most from remote monitoring [15], have a large number of Black and Latino individuals with higher melanin content and obesity rates compared with White individuals [16]. Recent notable data from the Centers for Disease Control and Prevention further stress these concerns by exposing that non-Hispanic Black individuals not only have significantly higher hypertension prevalence than non-Hispanic White individuals but also witness significantly lower hypertension control rates [17,18]. Affordable remote monitoring options have the responsibility to combat not only social determinants of health, such as access to health care and income, but also in turn the existing health disparities that are byproducts of them. As a result, there exists a glaring hole in PTT-based BP monitoring - that this technology has yet to be tested on the population for whom it may be the most valuable, and until now, its continuing practice will only exacerbate existing health disparities.

\section{Objectives}

In our previous work, we designed a wearable, multimodal, wrist-worn PTT monitoring device (SeismoWatch) and validated it in both controlled lab [19] and unsupervised home [20] settings, primarily on young, healthy persons with lighter skin. In this paper, we expand upon our previous work with a community-engaged research strategy that leverages expertise from a nonprofit organization serving MUAs in Georgia and evaluated our device in a more diverse population. We present our device's ability to accurately estimate BP in this diverse population and capture significant demographic-level differences in underlying arterial stiffness that coincide with observations from existing literature, through the calibration coefficients used in our BP estimation model. This work represents the first time that a noninvasive, cuffless, PTT-based wearable device has been extensively evaluated in a community-based diverse population as a potentially reliable and convenient monitoring option toward, ultimately, the remote screening and management of hypertension for health equity.

\section{Methods}

\section{Study Protocol}

A comprehensive breakdown of the demographics of the study population is presented in Table 1. This study was conducted under a protocol approved by the Georgia Institute of Technology institutional review board (protocol number H19251). The study was separated into two different populations ( $\mathrm{N}=44$ participants) referred to throughout this work as follows: (1) a young and healthy homogeneous population (first cohort=26 participants) and (2) an older, entirely Black, higher BMI, metropolitan population (second cohort=18 participants) recruited later through the help of our community outreach partners-a nonprofit organization serving medically underserved persons in the state of Georgia. For the first cohort, 26 (19 males and 7 females) young and healthy volunteers (mean age 26.7 years, SD 3.7; mean weight $73.8 \mathrm{~kg}$, SD 14.1; height $173.9 \mathrm{~cm}$, SD 9.6; and mean BMI $24.2 \mathrm{~kg} / \mathrm{m}^{2}$, SD 3.2) with no previous history of cardiovascular disease were recruited, and written informed consent was obtained. For the second cohort, 18 (6 males and 12 females) Black participants (mean age 44.1 years, SD 11.7; mean weight $94.4 \mathrm{~kg}$, SD 18.0; mean height $169.6 \mathrm{~cm}$, SD 11.5; and mean BMI $33.2 \mathrm{~kg} / \mathrm{m}^{2}$, SD 7.6) with no previous history of cardiovascular disease other than 
hypertension were recruited from the Atlanta metropolitan area, written informed consent was obtained, and further demographic information was collected post hoc with verbal consent. Both hypertensive status and the use of regular prescription medications were self-reported.

Table 1. Participant demographics and cardiovascular parameters for study participants (grouped by cohort; N=44).

\begin{tabular}{|c|c|c|c|}
\hline Demographics and cardiovascular parameters ${ }^{\mathrm{a}}$ & $\begin{array}{l}\text { Homogenous data set (first co- } \\
\text { hort; } n=26 \text {; participant } 1-26 \text { ) }\end{array}$ & $\begin{array}{l}\text { Community outreach (metropolitan Atlanta) data } \\
\text { set (second cohort; } n=18 ; \text { participant 27-44) }\end{array}$ & $P$ value \\
\hline Age (years), mean (SD) & $26.7(3.7)$ & $44.1(11.7)$ & $<.001$ \\
\hline \multicolumn{4}{|l|}{ Sex, n (\%) } \\
\hline Male & $19(73)$ & $6(33)$ & $\mathrm{N} / \mathrm{A}^{\mathrm{b}}$ \\
\hline Female & $7(26)$ & $12(67)$ & N/A \\
\hline Height $(\mathrm{cm})$, mean $(\mathrm{SD})$ & $173.9(9.6)$ & $169.6(11.5)$ & .19 \\
\hline Weight (kg), mean (SD) & $73.8(14.1)$ & $94.4(18.0)$ & $<.001$ \\
\hline $\mathrm{BMI}^{\mathrm{c}}\left(\mathrm{kg} / \mathrm{m}^{2}\right)$, mean (SD) & $24.2(3.2)$ & $33.2(7.6)$ & $<.001$ \\
\hline Obesity class, n (\%) & & & N/A \\
\hline I & $1^{\mathrm{d}}(4)$ & $2^{\mathrm{e}}(11)$ & \\
\hline II & N/A & $3^{\mathrm{f}}(17)$ & \\
\hline III & N/A & $4^{\mathrm{g}}(22)$ & \\
\hline Race, $n(\%)$ & & & N/A \\
\hline Black & $1^{\mathrm{h}}(4)$ & $18(100)$ & \\
\hline Other race & $25(96)$ & N/A & \\
\hline Hypertensive status, $\mathbf{n}(\%)$ & & & N/A \\
\hline Normotensive & $26(100)$ & $15(83)$ & \\
\hline Hypertensive & N/A & $2^{\mathrm{i}}(11)$ & \\
\hline Hypotensive & N/A & $1^{\mathrm{j}}(6)$ & \\
\hline Current medications, n (\%) & & & N/A \\
\hline Hydrochlorothiazide (1×day) & N/A & $2^{\mathrm{k}}(11)$ & \\
\hline Lisinopril (1×day) & N/A & $1^{1}(6)$ & \\
\hline Iron supplement & N/A & $1^{\mathrm{m}}(6)$ & \\
\hline
\end{tabular}

${ }^{a}$ Statistical significance between groups in values, where applicable, was computed using an unpaired two-tailed t test.

${ }^{\mathrm{b}} \mathrm{N} / \mathrm{A}$ : not applicable.

${ }^{\mathrm{c}}$ Obesity classified using the BMI per the guidelines from the National Heart, Lung, and Blood Institute of the National Institutes of Health [21] (I: BMI=30-34.9; II: BMI=35-39.9; III: BMI $\geq 40$ ).

${ }^{\mathrm{d}}$ Participant 23.

${ }^{\text {e}}$ Participants 30 and 43 .

f Participants 38, 40, and 42.

$\mathrm{g}_{\text {Participants } 34,36,37 \text {, and } 41 .}$

${ }^{\mathrm{h}}$ Participant 5 .

${ }^{\mathrm{i}}$ Participants 29 and 37.

${ }^{\mathrm{j}}$ Participant 33 .

${ }^{\mathrm{k}}$ Participants 29 and 37.

${ }^{1}$ Participant 29.

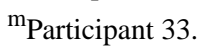

The concept of the study design is shown in Figure 1. Although not explicitly shown, two versions of the SeismoWatch were used in this study: a previous version of the hardware with comparable sensors was used in the young, homogeneous population (ie, the first cohort), before being adapted for a more robust, portable, and multimodal wearable device used in the 
metropolitan Atlanta population (ie, the second cohort) Specifically, the data from these cohorts were collected during two intervals, between which the hardware was revised to incorporate multiwavelength PPGs before investigating the performance of the sensing modality in the underrepresented population. This was essential to assess the efficacy of shorter-wavelength LEDs (ie, those with shallower skin penetration depths) in a Black population. However, in both the correlations in Figure 2 and calibration coefficient comparisons in Figure 3, only the results derived from the infrared (IR) PPGs, available to both devices, were computed and shown. The other key sensing components and reference system components were essentially identical: (1) the first version of the device used an analog version of the accelerometer (ADXL354, Analog Devices) to acquire the SCG, whereas the second version simply used the digital version of the same sensor (ADXL355, Analog Devices) to reduce size and (2) the finger-cuff continuous BP reference system (ccNexfin, Edwards Lifesciences) along with the data acquisition module (MPU150, Biopac Systems) were identical in both studies.

Figure 1. Concept overview and study design. Sensor information and placement locations for wearable system (blue) and reference system (purple). Noninvasive pulse transit time (PTT) measurement concept overview using seismocardiogram (SCG) and photoplethysmogram (PPG) sensors. Study protocol tasks in chronological order with duration and mean (SD) of mean arterial pressure (MAP) values for each task. Sample filtered signals from the participant with the lowest signal-to-noise ratio (SNR) signals $(n=37)$ : a hypertensive, high BMI, older Black female. In order from top to bottom: electrocardiogram (ECG), SCG, infrared PPG, red PPG, green PPG signals measured from the wearable system (blue) and the synchronized ECG, and arterial blood pressure (ABP) signals measured by the reference system (purple). Systolic blood pressure (SBP; top) and diastolic blood pressure (DBP; bottom) plotted across the full protocol for participant 37, with rest periods (green) and perturbations used to modulate BP (red) highlighted in chronological order, and the location where the reference finger-cuff continuous blood pressure (BP) system was paused during the exercise indicated. ABP: arterial blood pressure; BP: blood pressure; DBP: diastolic blood pressure; ECG: electrocardiogram; LED: light-emitting diode; PD: photodiode; PPG: photoplethysmogram; PTT: pulse transit time; SBP: systolic blood pressure; SCG: seismocardiogram.
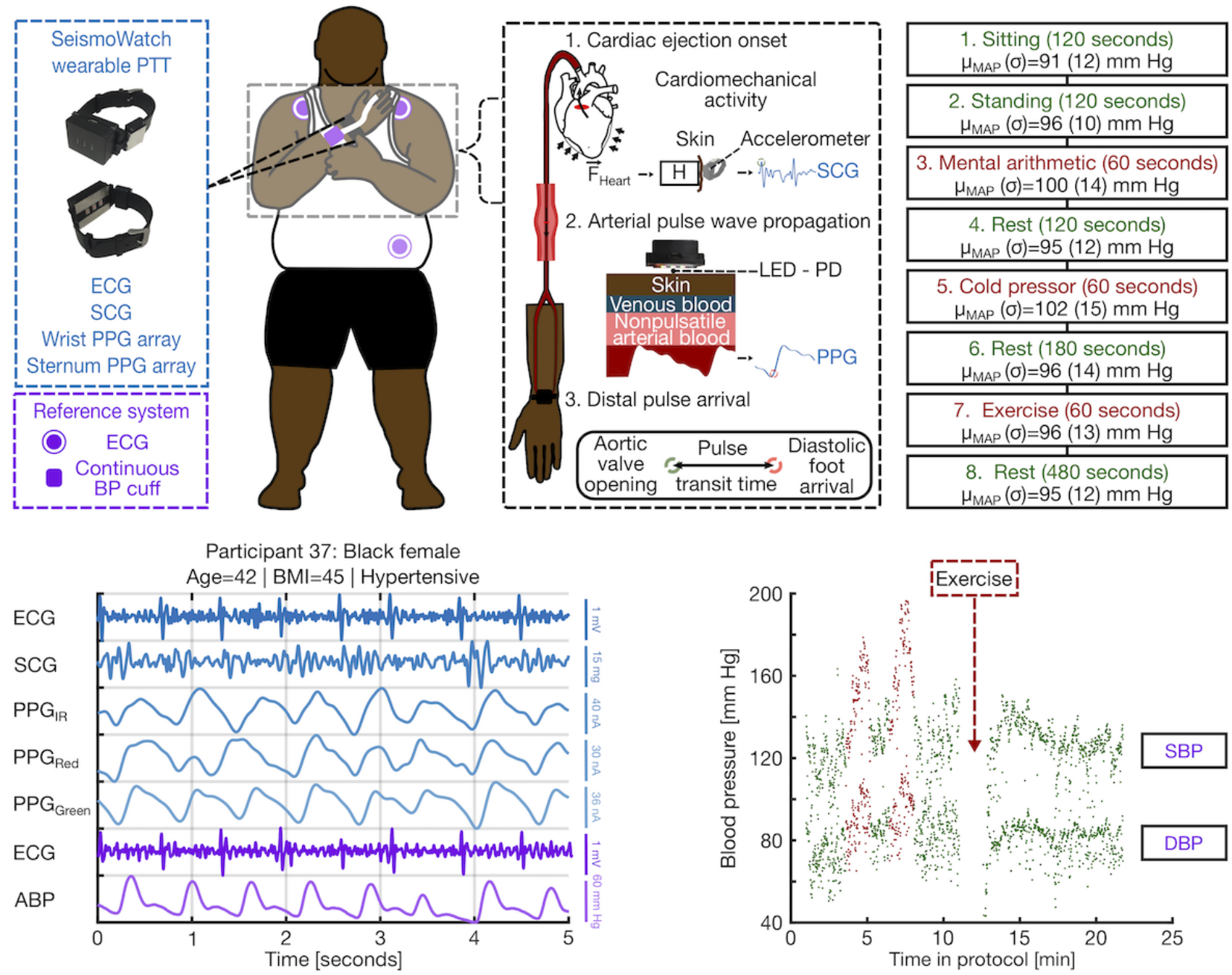
Figure 2. Wearable pulse transit time (PTT)-based blood pressure (BP) estimation results. Correlation and Bland-Altman plots between PTT-estimated $\mathrm{BP}$ and the finger-cuff continuous BP for mean arterial pressure, diastolic blood pressure, and systolic blood pressure estimation. The root mean squared error and the mean absolute difference for each correlation are shown. DBP: diastolic blood pressure; MAD: mean absolute difference; MAP: mean arterial pressure; PTT: pulse transit time; RMSE: root mean square error; SBP: systolic blood pressure.
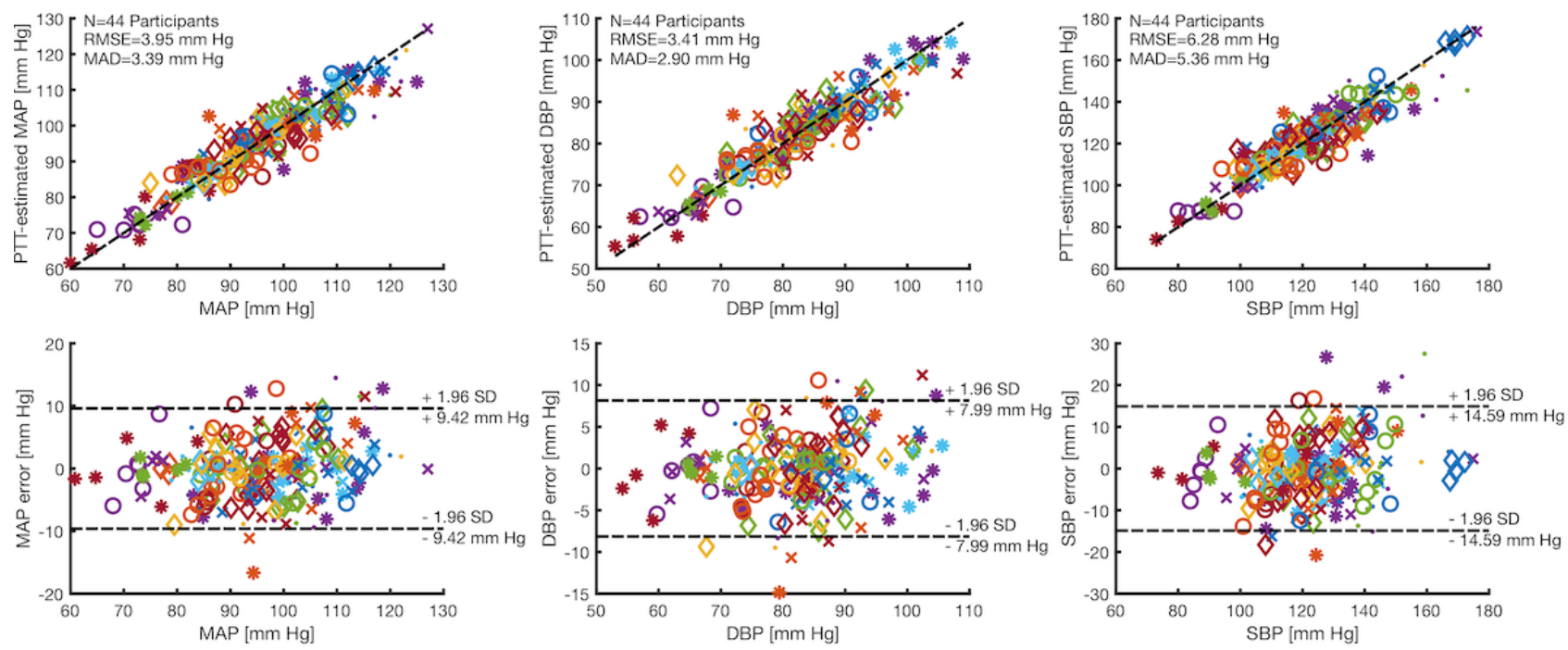

Figure 3. Participant-specific diastolic blood pressure (DBP) calibration coefficients are significantly different in demographics with typical disparities in arterial stiffness. Boxplots showing the statistically significant $\left({ }^{*} P<.05\right.$; Mann-Whitney U) difference in the DBP K1 and K2 calibration coefficients between participants who are nonobese and obese. Boxplots showing the statistically significant $(* P<.05$; Mann-Whitney U) difference in the DBP K1 calibration coefficients between male and female participants. Boxplots showing the statistically significant $(* P<.05$; Mann-Whitney $\mathrm{U})$ difference in the DBP K1 calibration coefficients between participants of other race and Black participants. Boxplots showing the difference in the DBP K1 and K2 calibration coefficients between young and older participants. DBP: diastolic blood pressure.

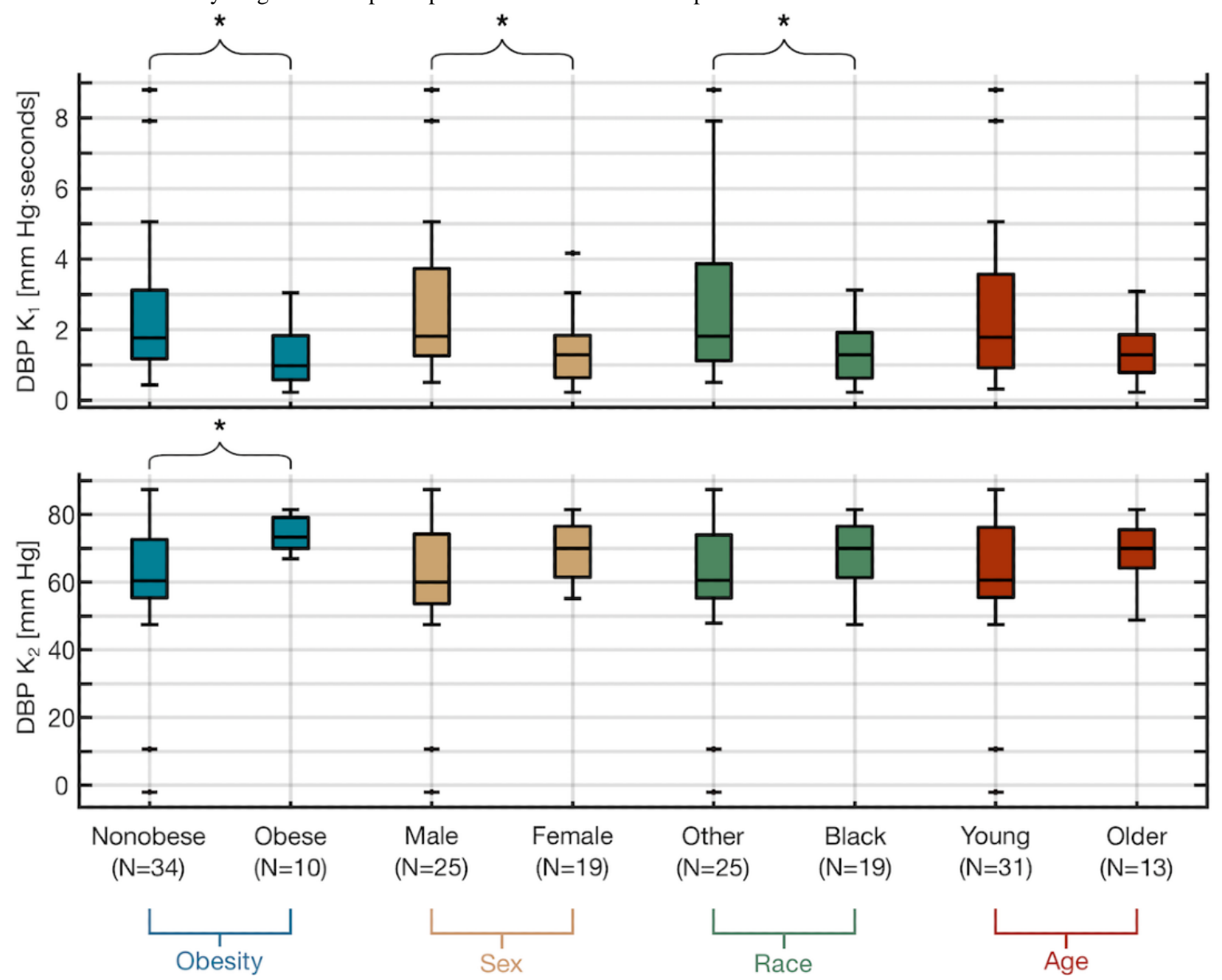

To acquire a timing reference for the start of a cardiac cycle, while serving as a reference for alignment to the wearable system signals, a wireless electrocardiogram (ECG) module

(BN-EL50, Biopac Systems) was attached to the participant in a three-lead configuration with $\mathrm{Ag} / \mathrm{AgCl}$ gel electrodes as shown in Figure 1. As depicted in Figure 1, a finger-cuff BP sensor 
based on the volume-clamp methodology (ccNexfin, Edwards Lifesciences) $[22,23]$ was placed on the same hand as the watch, acquiring a reference measurement of continuous beat-by-beat BP. Although volume-clamping continuous BP devices are not the clinical gold standard for ABP measurements, an arterial line was not feasible due to invasiveness, and a sphygmomanometer was not used because of the need for a trained professional and lack of beat-by-beat BP data. Similarly, semiautomated BP cuffs were not used as they hinge on following strict guidelines to obtain an accurate reading, such as being seated and resting the arm at heart level, which were impossible to satisfy simultaneously while acquiring watch measurements, given the need for the contralateral hand to touch the ECG electrode to activate the PTT mode [20]. In addition, it was recently demonstrated that a volume-clamping-based system had comparable accuracy with noninvasive oscillometric BP cuffs [24]. All reference system sensors were sampled at 1 $\mathrm{kHz}$ and interfaced to a computer using a data acquisition system (MPU150, Biopac Systems) and its corresponding software (Acqknowledge, Biopac Systems). The reference system files were saved to a desktop computer for postprocessing.

Participants were asked to change into either a V-cut T-shirt or tank top, if not wearing one already, to acquire the sternal PPGs included in the wearable designs, though not examined in this work. The watch was fitted such that the PPGs faced the radial artery on the ventral side of the wrist. To capture the PTT, the participant performed a simple maneuver to place the watch on the sternum to acquire the SCG for the proximal timing reference, as shown in Figure 1, whereas the PPGs were sampled at both the sternum and wrist. Although this offers a noncontinuous assessment, routine remote BP monitoring using oscillometric devices has already demonstrated clinical value, although it does not offer continuous BP measurement [2]. Specifically, ambulatory BP monitors, due to their superior portability and measurement frequency — comparable with what this wearable device can easily provide [20]- have become invaluable for the screening and management of hypertension [2] such that the added benefit of continuous BP measurement may only be marginal.

In order, the participants went through a 2-minute baseline period while sitting before obtaining another 2-minute baseline measurement while standing. Then, a series of perturbations with varying rest periods in between were used to modulate BP. First, a mental arithmetic exercise was used to increase BP [12], in which participants were given a three-digit integer and were told to add the sum of the digits to the number repeatedly for 1 minute. Then, a cold pressor test was conducted in which participants submerged their hand contralateral to the watch in a bucket of ice water for as long as tolerable or until the full minute. Finally, during the exercise session, the finger cuff was removed to avoid damage, and the participant performed either a stair stepping or bicycling exercise, based on personal preference, for 1 minute. As mentioned in our previous work [20], the new version of the watch enters the PTT measurement mode when the user places a finger from their hand contralateral to the watch on the positive wrist ECG electrode; therefore, we were unable to acquire PTT data during exercise for both cohorts and cold pressor for the participants in the second cohort (ie, second cohort). Although with the newer hardware, we were unable to collect PTT data during the cold pressor perturbation for the second cohort, the effect of the cold pressor-assessed directly after the hand was removed from the ice water (ie, a maximum of 1 minute after immersion) — was still well within its physiological window during the following rest period [25]. Overall, as our device is not designed to offer continuous measurements of BP, examining the effect of these perturbations in the rest period directly following them, similar to our previous work [19], still allowed for a comprehensive evaluation of the methodology in a diverse population. However, PTT data from the first cohort during the cold pressor were still used. As the BP data from the cold pressor test were still acquired for the second cohort, as the continuous BP cuff was still on, the mean arterial pressure (MAP) values were factored into the ones displayed in Figure 1. To do so, a $50 \mathrm{~ms}$ moving average filter was applied to the measured continuous BP signal, ensemble averages of 10 heartbeats with $50 \%$ overlap were taken, and the $\mathrm{BP}$ beat with the highest signal-to-noise ratio (SNR) was selected.

\section{Signal Processing}

The signal processing pipeline is shown in Figure 4. All signal processing and statistical analyses were performed in MATLAB R2018a (MathWorks). Before preprocessing the SCG and PPG signals acquired from the wearable system, it was imperative to time-align them to the continuous BP signal from the reference system using the respective ECGs to ensure proper temporal comparison. Specifically, the ECGs from each system were first filtered using a digital finite impulse response bandpass filter (BPF; fpass=10-40 Hz) to remove baseline wander due to postural sway and extract the R-wave, which was then identified using a simple peak detection algorithm. Then, cross-correlation was used to align the R-peaks of the two ECG readings by detecting the amount of lead and truncating either the wearable or reference signals depending on the condition. After alignment, the dorsoventral axis of the SCG (ie, z-axis acceleration) and green, red, and IR wrist PPGs were filtered using a digital finite impulse response BPF with bandwidths of 1-40 Hz and 1-8 Hz, respectively, to remove their out-of-band noise and baseline wander due to respiration. In addition, the continuous $\mathrm{ABP}$ waveform was smoothed using a $50 \mathrm{~ms}$ moving average filter. 
Figure 4. Signal processing pipeline. Block diagram of signal processing overview showing signal alignment using electrocardiogram signals acquired from the wearable system (blue) and reference system (purple) before bandpass filtering, heartbeat windowing, and photoplethysmogram (PPG) selection. After beat selection and signal quality assessment, the pulse transit time is computed as the aortic valve opening point of the seismocardiogram to the diastolic foot of the PPG. Calibration is used to estimate blood pressure (BP) using the arterial blood pressure waveform acquired from the continuous BP finger-cuff. Block diagram of the custom PPG selection algorithm, locating beats with greater systolic upstrokes and signal-to-noise ratio (SNR). ABP: arterial blood pressure; AO: aortic valve opening; BP: blood pressure; BPF: bandpass filter; ECG: electrocardiogram; PPG: photoplethysmogram; PTT: pulse transit time; SBP: systolic blood pressure; SCG: seismocardiogram; SNR: signal-to-noise ratio.

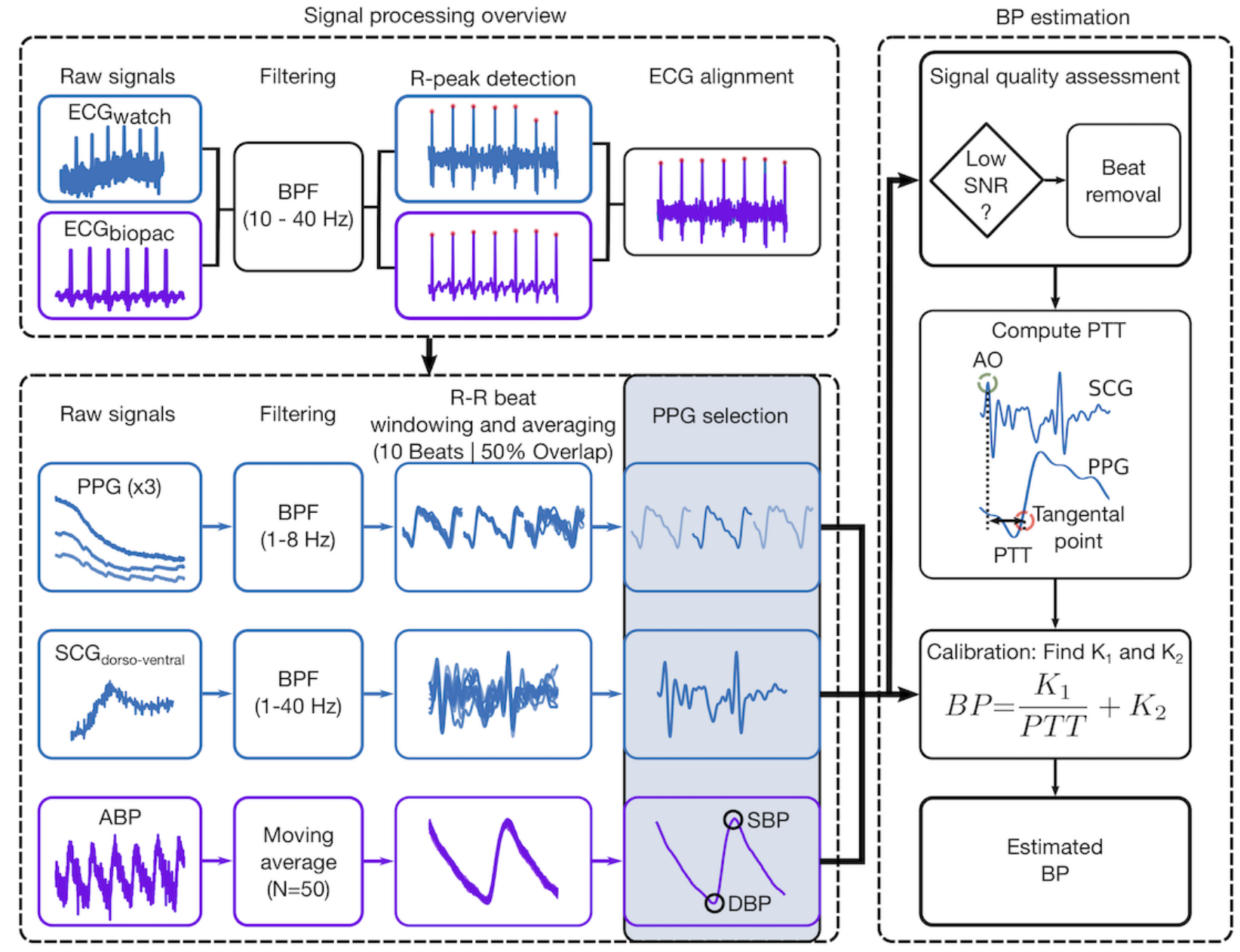

PPG Selection Algorithm

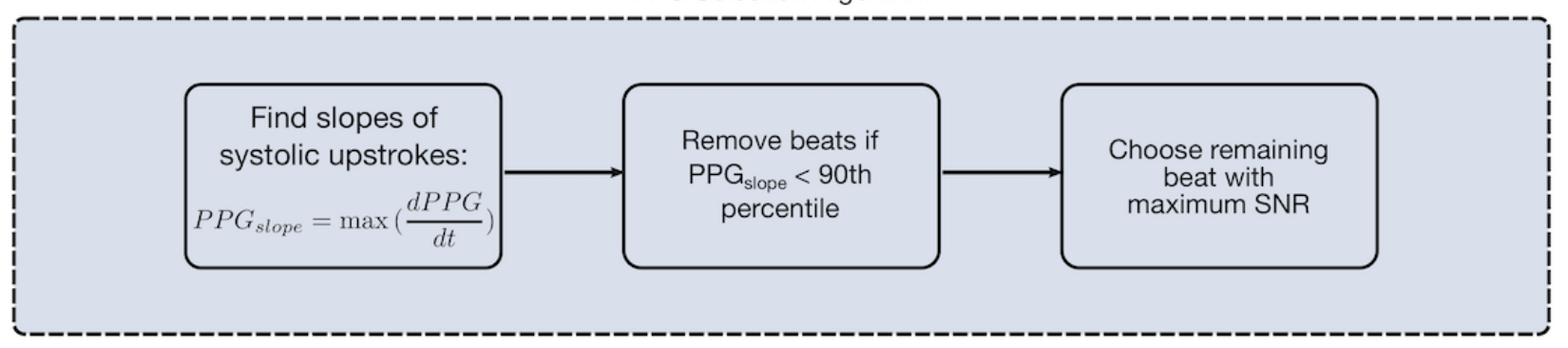

Next, the filtered and aligned SCG, PPG, and ABP waveforms were split into separate heartbeats using the detected R-R intervals of the synchronized ECG. Then, these heartbeat-indexed signals were ensemble-averaged using 10-beat windows with $50 \%$ overlap before assessing the signal quality to select the highest quality beat per task for each participant, similar to the methods used in our previous works $[19,20]$. Given the number of high BMI participants in this population, the SCG not only had a lower mean SNR when compared with our previous studies but was also observed to have less variability than the PPG SNR; hence, an emphasis was placed on determining the optimal PPGs first. In addition, upon an initial assessment of signal quality, it was observed that when the PPG signal had the highest SNR, typically, the SCG signal did as well-perhaps because acquiring a clean PPG signal inherently hinges on applying consistent pressure. The optimum PPG was selected using a physiologically inspired algorithm to first identify the beats with the top $10 \%$ of systolic upstrokes (ie, maximum of the derivative of the PPG waveform) and then select the remaining beat with the maximum SNR. The SNR 
was calculated using a noise-to-signal ratio detection algorithm detailed in Inan et al [26]. The methods used to determine the timing references for PTT calculation, the foot of the PPG, and the aortic valve opening (AO) point of the SCG were the same as those used in our previous studies [19,20]. Specifically, the foot of the PPG was computed using the intersecting tangent method described in the study by Mukkamala et al [12], and the AO point was assumed to be the first peak in each ensemble-averaged window before the foot of the PPG. Occasionally, the SCG signal was manually annotated to impose realistic constraints for the $\mathrm{AO}$ point or to ensure that the same morphological peak was consistently chosen for all tasks per participant. Participant-specific SNR thresholds were set to retain only high-fidelity signals; if the SNR of the SCG, PPG, or ABP beats was not greater than the prescribed cutoff, or if the foot of the PPG was not within a realistic range, then the respective ensemble-averaged waveforms were deemed too noisy for use and that task was not used for PTT calculation. Notably, the continuous reference BP allowed for the ability to evaluate the SNR of the ABP signal and incorporate this quality assessment into our signal processing pipeline to remove beats with low SNR reference measurements. After the entire signal quality assessment process, at least four of the tasks were used for BP estimation per participant. Finally, the PTT was calculated as the difference of the proximal timing reference, AO point of the paired SCG, and distal timing reference, the foot of the selected PPG. In addition to wavelength comparisons, the green and red wavelength PPGs were not used as the IR wavelength wrist PPGs had the highest mean SNR, because of the greater indifference of the IR wavelength to melanin absorption and the ability to capture more pulsatile arteries deeper in the tissue than cutaneous capillaries [12,27].

In addition, the postexercise recovery period was separated into an early and late rest period based on when the BP reached a consistent value. This allowed us to capture both the immediately heightened cardiac output-induced BP increase postexercise and the recovery back to baseline, while opportunely adding another PTT and BP data point for linear regression.

\section{Statistical Analysis}

Simple linear regression was performed independently between wearable participant-specific inverse PTT $\left(\mathrm{PTT}^{-1}\right)$ and reference diastolic blood pressure (DBP), MAP, or systolic blood pressure (SBP) value pairs, to calculate the calibration coefficients necessary to estimate each of the three BP components per participant; nonlinear models, whereas potentially more accurate, dictate the need for more calibration points [12,28]. Therefore, the resulting calibration coefficients-used to estimate BP from the conventional PTT-based BP estimation model shown in equation 1 -are merely the slope (ie, slope calibration coefficient $\left[\mathrm{K}_{1}\right]$ ) and y-intercept (ie, Y-intercept calibration coefficient $\left[\mathrm{K}_{2}\right]$ ) of the line of best fit [12]. This was identical to the calibration methods used in our previous work $[19,20]$.

$$
B P=\left(K_{1} / P T T\right)+K_{2}(\mathbf{1})
$$

The mean absolute difference (MAD) was computed from the mean of the absolute value of the difference between the estimated and reference BP. The benchmarks for MAD were chosen based on the Institute for Electronics and Electrical Engineers (IEEE) standard for wearable cuffless BP measuring devices [29]. In addition, the root mean square error (RMSE), calculated as the root mean square of the difference between the estimated BP and measured BP, was computed because of its enhanced sensitivity to outliers.

We stratified the entire study population for the demographic comparisons of the calibration coefficients shown in Figure 3, based on four factors (ie, obesity, sex, race, and age) known to affect arterial stiffness [30-35] and therefore the PTT. The participants were split into nonobese and obese groups based on the guidelines from the National Heart, Lung, and Blood Institute of the National Institutes of Health defining a BMI $\geq 30$ $\mathrm{kg} / \mathrm{m}^{2}$ as obese [21]. Thus, the nonobese group had a BMI $\leq 30$. To assess differences due to age, we separated the participants into younger (aged $\leq 40$ years) and older groups (aged $\geq 40$ years). Statistical significance $(P<.05)$ between demographic data for each cohort was assessed using an unpaired two-sample, two-tailed $t$ test, as shown in Table 1 .

For the demographic DBP calibration coefficient comparisons, a one-sample Kolmogorov-Smirnov test was used on each data point to test for normality, which determined that none of the data for the comparisons were normally distributed. Then, a Mann-Whitney U test (ie, Wilcoxon Rank Sum test) was used to assess statistical significance $(P<.05)$ among the unpaired data.

For the PPG wavelength DBP estimation comparisons-only applicable to the second cohort population due to the differences in hardware used-first, a one-sample Kolmogorov-Smirnov test was used on each data point to test for normality, which determined that none of the data for the comparisons were normally distributed. Then, a Wilcoxon Signed Rank test was used to assess statistical significance $(P<.05)$ among the paired data.

\section{Results}

\section{Multimodal Engineering Mechanics of the SeismoWatch}

The previous version of the watch, not shown in this work, consisted of a 3D printed case embedded with an accelerometer, PDs, and IR LEDs. All sensors were connected to a small external circuit box with straps for the participant to wear around the waist. The output of the analog accelerometer (ADXL354, Analog Devices) was connected to an analog front end (AFE) in the circuit box. To amplify the SCG signal and prevent saturation of the alternating current components owing to the varying direct current levels, the AFE separated the direct current and alternating current components using a low pass ( $\mathrm{fc}=1 \mathrm{~Hz} ; \mathrm{G}=-10 \mathrm{~dB}$ ) and BPF (fpass $=0.2 \mathrm{~Hz}-40 \mathrm{~Hz}$ ) in parallel. An analog adder recombined both components. For PPG measurements, the cathode of the PDs (S2386-18k, Hamamatsu Photonics) was connected to transimpedance amplifiers configured as a low-pass filter $(\mathrm{fc}=12 \mathrm{~Hz} ; \mathrm{G}=110 \mathrm{~dB}$ ) followed 
by gain and filter stages (fpass $=0.5-12 \mathrm{~Hz} ; \mathrm{G}=59 \mathrm{~dB}$ ). Finally, the ECG was acquired by placing 3 copper dry electrodes on the wrist band of the watch with 2 on the inside in contact with the wrist and 1 on the outside to place the index and middle finger. The 2 on the inside act as the right leg drive electrode and the positive lead, whereas the outside electrode is the negative lead. All electrodes were connected to an AFE (AD8232, Analog Devices) for ECG measurements. A microcontroller (Teensy 3.6, PJRC LLC) sampled the output of the accelerometer, PPG, and ECG AFE at $1 \mathrm{kHz}$. An onboard SD card was used to store the raw data for postprocessing, and a 1.2 Ah lithium-ion rechargeable battery was used to power the system. All instrumentation details were adopted from our previous work, with minor revisions [19].
The updated hardware, pictured in Figure 5, added modalities of sensing (ie, a gyroscope), included multiple wavelengths of LEDs for comparison with IR, improved the form factor for comfort and ease of use, and featured embedded systems innovations leveraged in this study. A more thorough description of the revised hardware is available in our most recent work [20]. An example of the serviceable automatic LED current scaling algorithm, detailed in our previous work [20], is highlighted in Figure 5. This proved to be an integral part of enabling this work; by adaptively adjusting the LED drive current, we were able to prevent saturation and variable PPG signal quality caused by varying contact pressure and, more importantly, prominent differences in skin tone among participants.

Figure 5. Pertinent multimodal hardware block diagram and adaptive light-emitting diode (LED) scaling. Main board with ATSAM4LS8 microcontroller $(\mu \mathrm{C})$, ADXL355 triaxial accelerometer, BMG250 triaxial gyroscope, and BME280 environmental sensor using the serial peripheral interface for fast communication supporting higher sample rates. Sensor board used to acquire wrist photoplethysmogram (PPG) and electrocardiogram signals. Automatic LED current scaling in operation during data collection: showing an increase in contact pressure and subsequent saturation of the photodiode, mitigated by an automatic decrease in LED current and overall consequential improvement in PPG signal quality. ECG: electrocardiogram; LED: light-emitting diode; PD: photodiode; PPG: photoplethysmogram; RLD: right leg drive; SD: Secure Digital; SPI: Serial Peripheral Interface.
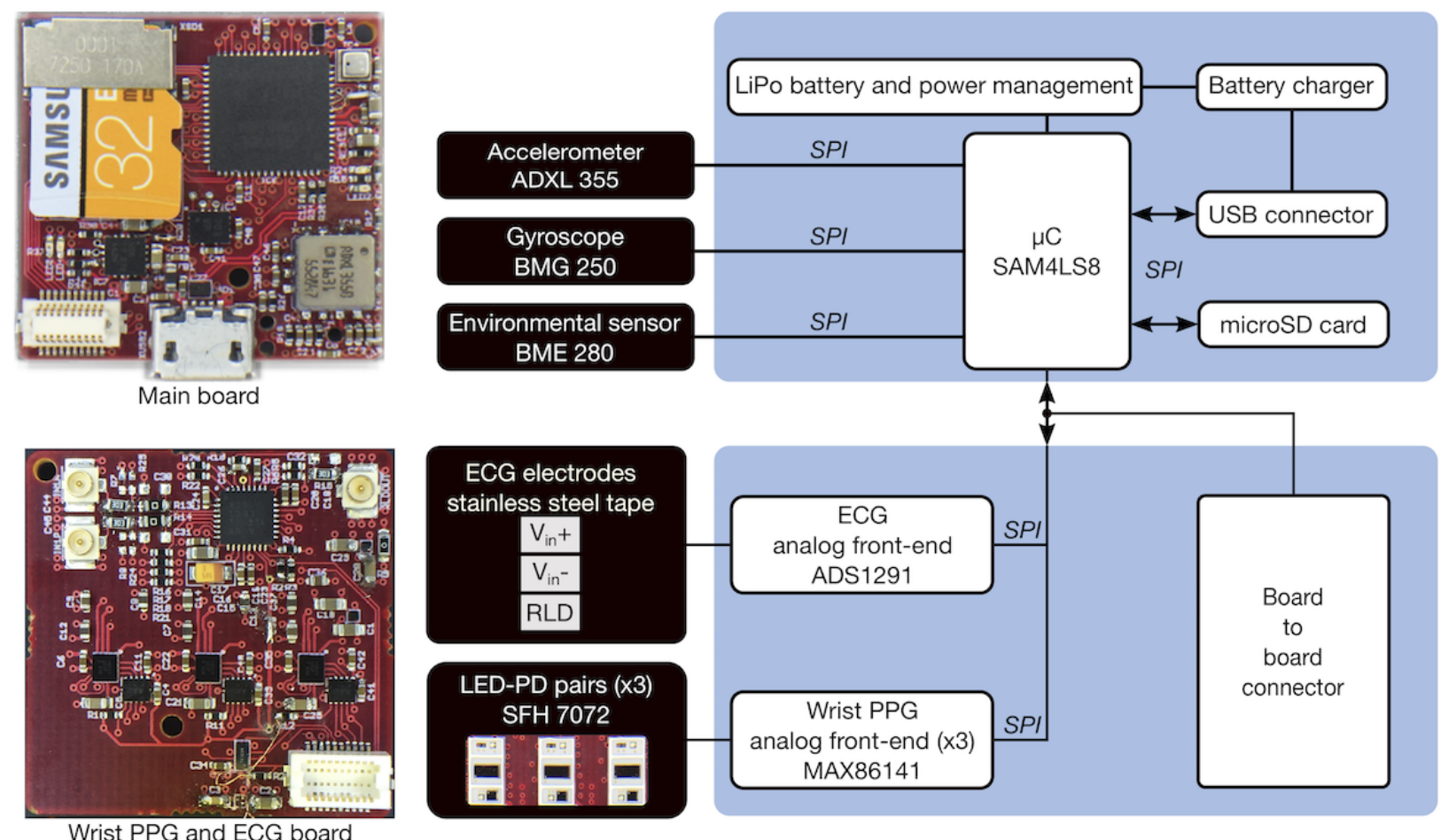

Automatic LED current scaling
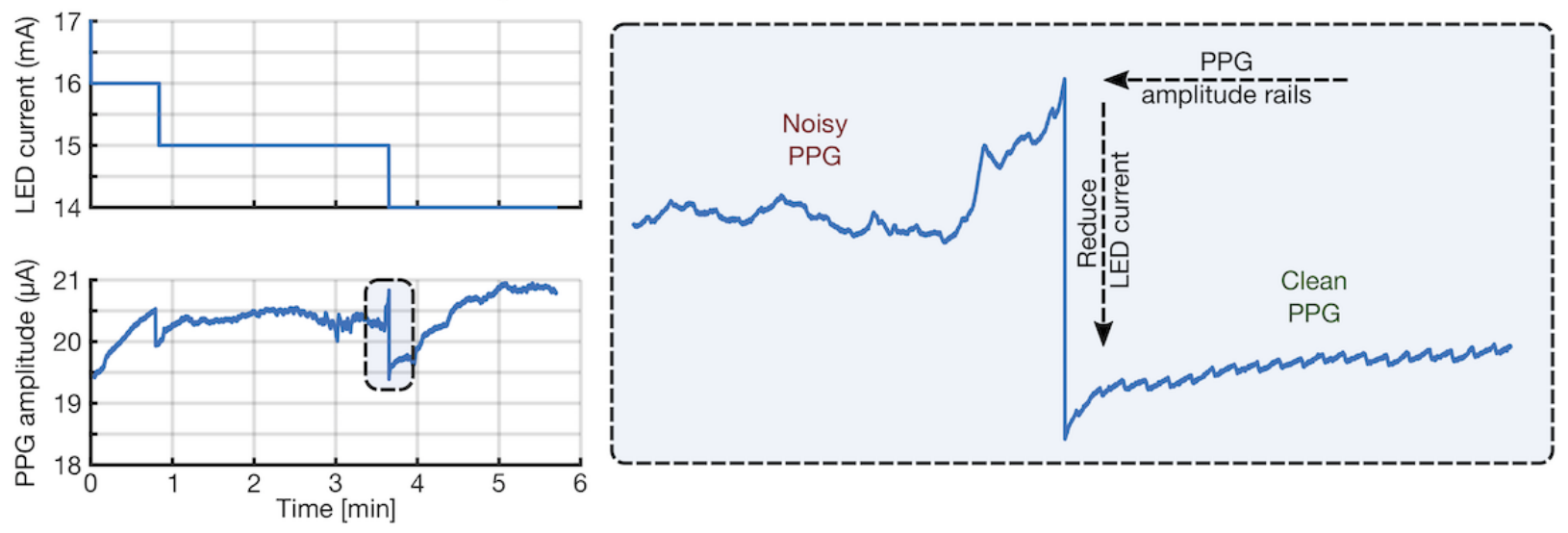


\section{Human Subject Studies in a Diverse Population}

All applicable results are presented as mean (SD). Figure 2 illustrates the correlation and Bland-Altman plots for our wearable PTT-based BP estimation of MAP, DBP, and SBP across all participants $(\mathrm{N}=44)$. The MAD was $2.90 \mathrm{~mm} \mathrm{Hg}$, $3.39 \mathrm{~mm} \mathrm{Hg}$, and $5.36 \mathrm{~mm} \mathrm{Hg}$ for DBP, MAP, and SBP, respectively. The mean RMSE was 3.41 (SD 2.01) $\mathrm{mm} \mathrm{Hg}$, 3.95 (SD 2.42) $\mathrm{mm} \mathrm{Hg}$, and 6.28 (SD 3.44) $\mathrm{mm} \mathrm{Hg}$ for DBP, MAP, and SBP, respectively. DBP and MAP estimation had better $95 \%$ CIs than SBP at $7.99 \mathrm{~mm} \mathrm{Hg}, 9.42 \mathrm{~mm} \mathrm{Hg}$, and $14.59 \mathrm{~mm} \mathrm{Hg}$, respectively. The mean Pearson correlation coefficient (PCC) was 0.67 (SD 0.16), 0.63 (SD 0.31), and 0.50 (SD 0.41) for PTT-based DBP, MAP, and SBP estimation, respectively.

The MAD for the individual study populations (first cohort=26 participants and second cohort=18 participants) was $2.69 \mathrm{~mm}$ $\mathrm{Hg}$ and $3.20 \mathrm{~mm} \mathrm{Hg}, 3.21 \mathrm{~mm} \mathrm{Hg}$ and $3.64 \mathrm{~mm} \mathrm{Hg}$, and 5.17 $\mathrm{mm} \mathrm{Hg}$ and $5.63 \mathrm{~mm} \mathrm{Hg}$, for DBP, MAP, and SBP estimation, respectively. The mean RMSE for the individual study populations (first cohort $=26$ participants and second cohort $=18$ participants) was 3.19 (SD 1.64) $\mathrm{mm} \mathrm{Hg}$ and 3.73 (SD 2.48) $\mathrm{mm} \mathrm{Hg}, 3.78$ (SD 2.06) $\mathrm{mm} \mathrm{Hg}$ and 4.18 (SD 2.90) $\mathrm{mmHg}$, and 6.26 (SD 3.25) $\mathrm{mm} \mathrm{Hg}$ and 6.32 (SD 3.80) $\mathrm{mm} \mathrm{Hg}$ for DBP, MAP, and SBP estimation, respectively. The mean PCC for the individual study populations (first cohort $=26$ participants and second cohort=18 participants) was 0.69 (SD 0.15) and 0.65 (SD 0.17), 0.68 (SD 0.23) and 0.55 (SD 0.38), and 0.58 (SD 0.33 ) and 0.39 (SD 0.49) for DBP, MAP, and SBP estimation, respectively.

The MAD for the 19 Black participants was $3.18 \mathrm{~mm} \mathrm{Hg}, 3.72$ $\mathrm{mm} \mathrm{Hg}$, and $5.84 \mathrm{~mm} \mathrm{Hg}$ for DBP, MAP, and SBP estimation, respectively. The mean RMSE for all 19 Black participants was 3.72 (SD 2.41) mm Hg, 4.29 (SD 2.86) $\mathrm{mm} \mathrm{Hg}$, and 6.69 (SD 4.03) $\mathrm{mm} \mathrm{Hg}$ for DBP, MAP, and SBP estimation, respectively. The mean PCC for all 19 Black participants was 0.64 (SD 0.17), 0.53 (SD 0.38), and 0.37 (SD 0.48) for DBP, MAP, and SBP estimation, respectively.

The MAD for the 10 participants who were obese was 2.69 $\mathrm{mmHg}, 3.17 \mathrm{~mm} \mathrm{Hg}$, and $5.02 \mathrm{~mm} \mathrm{Hg}$ for DBP, MAP, and SBP estimation, respectively. The mean RMSE for all 10 participants who were obese was 3.28 (SD 2.59) $\mathrm{mm} \mathrm{Hg}, 3.69$ (SD 3.00) $\mathrm{mm} \mathrm{Hg}$, and 5.71 (SD 4.18) $\mathrm{mm} \mathrm{Hg}$ for DBP, MAP, and SBP estimation, respectively. The mean PCC for all 10 participants who were obese was 0.65 (SD 0.18), 0.52 (SD 0.48), and 0.39 (SD 0.58) for DBP, MAP, and SBP estimation, respectively.

Figure 3 depicts the boxplots of the DBP calibration coefficients from our estimation model, $\mathrm{K}_{1}$ and $\mathrm{K}_{2}$, for four different demographic factors known to affect arterial stiffness: obesity, sex, race, and age. The DBP $\mathrm{K}_{1}$ and $\mathrm{K}_{2}$ values for nonobese $(\mathrm{N}=34)$ versus obese $(\mathrm{N}=10)$ participants are 2.38 (SD 1.99) $\mathrm{mm} \mathrm{Hg} / \mathrm{s}$ versus 1.20 (SD 0.88) $\mathrm{mm} \mathrm{Hg} / \mathrm{s}$ and 61.02 (SD 18.03) $\mathrm{mm} \mathrm{Hg}$ versus 74.31 (SD 5.14) $\mathrm{mm} \mathrm{Hg}$, respectively. The DBP $\mathrm{K}_{1}$ and $\mathrm{K}_{2}$ values for male $(\mathrm{N}=25)$ versus female $(\mathrm{N}=19)$ participants are 2.65 (SD 2.18) $\mathrm{mm} \mathrm{Hg} / \mathrm{s}$ versus 1.40 (SD 0.98) $\mathrm{mm} \mathrm{Hg} / \mathrm{s}$ and 60.16 (SD 20.64) $\mathrm{mm} \mathrm{Hg}$ versus 69.14 (SD 8.29) $\mathrm{mm} \mathrm{Hg}$, respectively. The DBP $\mathrm{K}_{1}$ and $\mathrm{K}_{2}$ values for non-Black
$(\mathrm{N}=25)$ versus Black $(\mathrm{N}=19)$ participants are 2.63 (SD 2.21) $\mathrm{mm} \mathrm{Hg} / \mathrm{s}$ versus 1.44 (SD 0.94) $\mathrm{mm} \mathrm{Hg} / \mathrm{s}$ and 60.66 (SD 20.29) $\mathrm{mm} \mathrm{Hg}$ versus 68.49 (SD 9.98) $\mathrm{mm} \mathrm{Hg}$, respectively. The DBP $\mathrm{K}_{1}$ and $\mathrm{K}_{2}$ values for young $(\mathrm{N}=31)$ versus older $(\mathrm{N}=13)$ participants are 2.38 (SD 2.09) $\mathrm{mm} \mathrm{Hg} / \mathrm{s}$ versus 1.47 (SD 0.87) $\mathrm{mm} \mathrm{Hg} / \mathrm{s}$ and 61.96 (SD 19.03) $\mathrm{mm} \mathrm{Hg}$ versus 69.00 (SD 9.22) $\mathrm{mm} \mathrm{Hg}$, respectively.

Both $\mathrm{K}_{1}$ and $\mathrm{K}_{2}$ were significantly different between the nonobese and obese populations $(P=.045$ and $P=.008$, respectively). The female $\mathrm{K}_{1}$ values were significantly $(P=.04)$ lower than those of their male counterparts. The $\mathrm{K}_{1}$ values for Black participants were significantly $(P=.047)$ lower than those of the other races.

For the participants in the second cohort-all Black-with whom we used the newer version of the hardware [20] that included green and red LEDs in addition to the IR, the PCC for DBP estimation was 0.38 (SD 0.34), 0.59 (SD 0.44), and 0.65 (SD 0.17) when using the green $\lambda=526 \mathrm{~nm}$, red $\lambda=660 \mathrm{~nm}$, and IR $\lambda=950 \mathrm{~nm}$ wavelength PPGs for the distal timing reference, respectively. The PCC for the IR and red wavelength PPGs was significantly $(P=.01$ and $P=.048)$ higher than that of the green wavelength PPGs. However, the corresponding mean DBP RMSE was 3.95 (SD 2.53) $\mathrm{mm} \mathrm{Hg}, 3.11$ (SD 2.33) mm Hg, and 3.73 (SD 2.48) $\mathrm{mm} \mathrm{Hg}$ for green, red, and IR, respectively.

\section{Discussion}

\section{Principal Findings}

To the best of our knowledge, this is the first study to accurately estimate DBP and MAP using noninvasive PTT measurements acquired from a holistic population, with considerable differences in body fat percentage, melanin levels, and vascular stiffness associated with age and hypertension. Furthermore, our SBP estimation is sufficient to be clinically recommended for monitoring $[29,36]$. We demonstrated the reliability of a convenient method for estimating BP and observed that our calibration coefficients were significantly different in characteristic demographic groups known to have increased arterial stiffness. This work represents a necessary advancement toward remote monitoring for persons in MUAs by enabling wearable PTT-based BP estimation, including through the comprehensive evaluation of a watch-based form factor conducive to obtaining ambulatory BP measurements in low-resource settings.

\section{Accurately Estimating BP in a Diverse Population Using a Multimodal Wearable Device}

We demonstrated the performance of our wrist-worn PTT-based device when used to estimate BP within a diverse population over the course of multiple unique perturbations. Our results for MAP and DBP passed the acceptable benchmarks for the BP estimation error set by the IEEE standard on wearable cuffless BP estimation devices (MAD $\leq 5 \mathrm{~mm} \mathrm{Hg}$ ) [29]. We were still able to achieve a reliable correlation between PTT and BP even with several demographic factors such as age, melanin levels, and BMI inherently influencing the measured optical-PPG and mechanical-SCG signals. 
The DBP estimation remained the most accurate, similar to our previous studies [19,20]; the foot of the PPG waveform, used as the distal timing reference, indicates the arrival of the pulse wave during end diastole. Similarly, the SBP estimation continued to perform the worst, as the peak of the pulse wave is the fiducial marker of the PPG that occurs during systole; however, the peak is not frequently extracted, as its true timing can be confounded by wave reflection interference, leading to unreliable PTT estimates [12]. Recent studies have demonstrated that the PTT computed using the diastolic foot of the PPG outperforms that using the systolic maximum for both DBP and SBP [37].

The DBP RMSE was relatively similar at both low and high values of DBP, which indicates that the diastolic foot was a dependable timing reference for calculating the PTT, irrespective of inherent participant-specific differences in BP. Although our SBP estimation was just outside the acceptable limits set forth by the IEEE standard (ie, MAD=5.36 $\mathrm{mm} \mathrm{Hg}$ vs $5.0 \mathrm{~mm} \mathrm{Hg}$ ) [29], this error translates to a grade B classification [29] and therefore would still be clinically recommended for monitoring SBP [36]. Furthermore, the SBP range studied in this work was greater than $100 \mathrm{~mm} \mathrm{Hg}$, substantially higher than that reported in previous studies in the literature for wearable cuffless BP estimation, and a combination of different perturbations was used to modulate BP. Using a single perturbation would have led to an improved correlation [12,14], as in our previous work where we had only used exercise [19]. However, a comprehensive evaluation of this methodology would be incomplete without a procedure consisting of a wide variety of perturbations with different known physiological responses and pathways to modulate BP [14]. In addition, as noted in Figure 1 , the exercise perturbation did not apparently produce a marked difference in BP due to several factors: (1) technical limitations in rapid calibration for the reference measurement (ie, finger-cuff continuous BP) and increased motion artifacts following exercise led to a greater percentage of beat removal in the early exercise section than any other task and (2) exercise does not necessarily consistently modulate $\mathrm{BP}$ in a predictable manner due to differences in participant-specific vasoactivity and contractility $[12,38]$.

Only the DBP was examined for further analyses conducted below because, as previously mentioned, the distal timing reference used in this work (ie, the foot of the PPG waveform) occurs during diastole and therefore provides the most reliable estimation of DBP out of the three BP components [12]. The dependability of the diastolic foot and our robust DBP estimation were necessary before performing in-depth analyses with confidence. Although elevated SBP is considered to be the greatest predictor of future cardiovascular risk [39,40], elevated DBP has nonetheless been shown to independently increase the risk of subsequent cardiac events [39,41]. In addition, DBP is a greater contributor to MAP, which in older patients with isolated systolic hypertension, when compared with an equivalent increase in pulse pressure, has been shown to be a comparable independent predictor of both stroke and all-cause mortality [42]. Finally, DBP has been shown to be a more significant predictor than SBP of new-onset hypertension in adults aged $\leq 50$ years $[40,43-45]$. This suggests that accurate
DBP estimation using a wearable device can efficiently be used to incentivize people to make healthy lifestyle modifications earlier in life, central to the World Health Organization's effort to reduce the global prevalence of hypertension [46].

\section{Essential Device Novelties Enabling Reliable PTT Computation}

For the first time, we demonstrated that noninvasive PTT measurements are reliable estimators of $\mathrm{BP}$ across a wide range of skin tones and BMI. Both DBP and MAP estimation for the 10 participants who are obese and 19 Black participants in this study were well under the IEEE requirement [29]. This was enabled by the highly sensitive hardware, multisensor approach, and automated LED current scaling that our custom wearable device offers [20]. The PPG array and adaptive LED current scaling allowed us to automatically mitigate poor signal quality issues due to misplacement, inherent differences in skin tone, and applied pressure that typically corrupts PPG signals. However, the most integral components of our PPG hardware were the IR wavelength LEDs.

We leveraged longer wavelengths of light for deeper penetration into the tissue to robustly acquire the PPG signal from arteries located deeper than the cutaneous vascular bed [12]. Cutaneous arteries are greatly affected by the changes in vascular tone expected from the perturbations we used to modulate BP herein (ie, cold pressor and exercise). Furthermore, as IR PPGs are more susceptible to motion artifacts than lower wavelength ones $[12,47]$, our PPG-first signal quality assessment not only avoided these motion artifact corrupted waveforms because of their low SNR but also avoided moments where the SCG quality would naturally suffer as well. However, even the red PPGs had a considerably larger SD in their PCC than the IR PPGs, possibly because the IR wavelength, when compared with red, is less sensitive to the oxygen content of hemoglobin and has approximately half the skin absorption coefficient in Black individuals $[12,27]$. Despite statistically significant differences in the PCC using IR and red PPGs rather than green PPGs, the actual DBP RMSEs were comparable. This implies that when using the green PPGs for participants with a low PCC, our signal quality assessment algorithm removed beats with greater $\mathrm{BP}$ variability, resulting in a lower SD of DBP and consequent RMSE. Although even green wavelength PPGs have demonstrated the ability to reliably extract heart rate across a wide variety of skin tones [48], our data suggest that these shorter wavelengths cannot be used to dependably compute the PTT in a diverse population. In addition, although unconventional, our watch was placed on the ventral side of the wrist, which allows for both higher quality, convenient SCG acquisition and enhanced PPG SNR due to viable access to the radial artery and less melanin content than the dorsal side [49]. Therefore, existing smartwatches, beginning to slowly incorporate cuffless, noninvasive BP methodologies, may face even greater difficulties in achieving accurate PPG measurements across a broad range of skin tones.

Finally, our physiologically inspired PPG selection algorithm - to first select the PPG signals with the greatest systolic upstrokes-had an important role in reducing the BP estimation error. PPG waveforms with greater systolic upstrokes 
(ie, maximum derivative of the PPG waveform) offer improved PTT estimates and are key indicators of BP stemming from larger, more pulsatile, elastic arteries with greater distensibility [12,50]. In addition, several recent machine learning (ML) approaches to use the PPG signal for BP estimation have shown that the systolic upstroke is one of the most important features of the waveform [51,52]. Hence, the selection algorithm, by extracting information from these more reliable and clinically important arteries, was a central part of our ability to notice the demographic differences in arterial stiffness rooted in our calibration coefficients.

\section{Calibration Coefficients Capture Demographic Differences in Arterial Stiffness}

We observed that the participant-specific calibration coefficients used in the standard linear PTT-BP estimation model for DBP, shown in equation 1 (ie, $\mathrm{K}_{1}$ and $\mathrm{K}_{2}$ ), are significantly different between subpopulations with large variations in demographic factors known to affect arterial stiffness. We selected the four demographic categories (ie, obesity, sex, race, and age) based on the literature, emphasizing these as major determinants of differences in arterial stiffness and therefore risk factors for hypertension [16,30-33,35,53,54].

The $\mathrm{K}_{1}$ value (ie, the slope of the line of best fit) is indicative of the underlying baseline vascular stiffness, whereas $\mathrm{K}_{2}$ (ie, the intercept) represents the inherently correlated bias in baseline BP $[12,55,56]$. At the same BP, persons with greater arterial stiffness have inherently faster pulse wave velocities (PWVs) and therefore shorter PTTs than persons with normal arterial stiffness [12]. The $\mathrm{K}_{1}$ value mitigates these differences in PTT-based estimation by capturing the intrinsic participant-specific arterial stiffness to output similar $\mathrm{B} P$ values. Therefore, with increasing arterial stiffness, we expected to find a lower $\mathrm{K}_{1}$ value and a higher $\mathrm{K}_{2}$ value, as observed in the PWV literature [55,56].

Obesity was the only comparison for which the differences in the $\mathrm{K}_{1}$ and $\mathrm{K}_{2}$ calibration coefficients were statistically significant. This coincides with the literature stating that obesity is one of the greatest age-normalized risk factors and contributors to arterial stiffness [57]. Otherwise, only the $\mathrm{K}_{1}$ values in the sex and race comparisons were statistically significant between the groups. Although it has been shown that both females and Black individuals have greater arterial stiffness than similar-age males and White individuals $[31,34,35]$, these two comparisons should be re-evaluated after increasing our recruitment. Approximately 47\% (9/19 participants) of both the female and Black population were also obese. The age comparison was not statistically significant, although the older population followed a similar trend of a lower $\mathrm{K}_{1}$ and higher $\mathrm{K}_{2}$. This finding is not surprising, as significant differences in arterial stiffness and substantial augmentations in arterial remodeling are typically examined in participants aged $\geq 50$ years $[32,58]$.

\section{Limitations and Future Work}

\section{Refining Population Demographics and Investigating PTT, K1, and K2 as Potential Digital Biomarkers of Arterial Stiffness}

Overall, although this data set captured a more representative population in the range of end users for which consistent BP monitoring is recommended [59], our PTT-based device should be further tested in an exclusively older (ie, age $>50$ years), morbidly obese (ie, BMI $>40 \mathrm{~kg} / \mathrm{m}^{2}$ ), and hypertensive population - with even distributions across sex, race, and skin tones along the Fitzpatrick scale - to truly understand the limits of this technology and supplement the findings herein.

Early vascular remodeling due to the demographic factors investigated in this work, not to mention socioeconomic factors affecting MUAs [15,16], predispose individuals who are obese and Black individuals to greater lifetime cardiovascular risk [30,35,57,60,61]. Therefore, future PTT-based BP estimation studies should closely monitor the calibration coefficients, $\mathrm{K}_{1}$ and $\mathrm{K}_{2}$, as potential intermediate digital biomarkers for longitudinal monitoring and the comparison of arterial stiffness among different persons [7]. Eventually, even PTT measurements, as PWV is already an independent predictor of arterial stiffness [62], may indicate subclinical differences in vascular resistance due to early stage arterial remodeling, the main precursor to hypertension [32].

\section{Reducing the Burden of Calibration}

Consistent recalibration poses a practical concern for PTT-based BP estimation. Hence, future studies should focus on evaluating the timeframe for which participant-specific calibration curves can reliably estimate BP and whether interparticipant and population-level curves can be sufficient. However, given the value of interpreting the calibration coefficients presented in this work, caution should be exercised due to the trade-off of sacrificing this potential usefulness when using generalized interparticipant models. Furthermore, the individual effects of the perturbations used to modulate BP in this experiment should be scrutinized, along with other exercises shown to substantially change BP [63-65]. The goal is to use perturbations that can consistently be leveraged to increase the dynamic range of BP measurements for calibration-critical to achieving optimal estimations at home in our previous work [20] and are achievable in low-resource settings.

\section{Leveraging ML and Hardware Advancements for Robust SCG AO Detection}

Similarly, to the instrumental role of the physiologically inspired PPG selection algorithm in this work, further exploration into automated SCG fiducial point detection algorithms may help extract the most informative SCG signals. Specifically, the SCG can be greatly affected by inaccurate placement of the watch; however, recent advancements using ML techniques have shown that the SCG waveform is modulated in a predictable manner during these placement inaccuracies [66]. Therefore, by interpreting these findings, one might be able to convert the measured SCG to the archetypal SCG or use a template-matching localization approach [67] for each 
participant before extracting salient features from the optimal waveform.

In addition, annotating the exact $\mathrm{AO}$ point can be challenging because the signal not only has appreciable interparticipant variability, especially in a population with considerable differences in BMI, but can also be corrupted by motion artifacts. Although our technique for extracting the AO point has led to a high correlation between PTT and BP, in both our recent work [20] and this one, for a few sessions, we manually annotated the SCG to impose realistic constraints for the range of the pre-ejection period (PEP) and selected a consistent morphological peak across all tasks per participant. Eventually, robust identification of this timing reference is necessary for reliable automatic PTT computation, as the main advantage of using the PTT over the pulse arrival time (ie, the time from the R-wave of the ECG to the diastolic foot of the PPG) for BP estimation is its ability to account for changes in the nonnegligible cardio-electromechanical delay, that is, the PEP $[12,68]$. Furthermore, examining the other sensor data available at our disposal, such as filtering the SCG in a higher bandwidth (ie, fpass $=30-125 \mathrm{~Hz}$ ) to retain the phonocardiogram signal indicative of valve closures, using the three-axis gyrocardiogram or simply the other axes of the SCG, could prove to help with improving PEP estimation as shown in previous work [19,69].

\section{Conclusions}

We have demonstrated that a wrist-worn device, using noninvasive PTT estimates, can reliably and conveniently track $\mathrm{BP}$ in a diverse population. Leveraging the ubiquity of wearable devices can empower users to make healthy lifestyle modifications such as exercise, which can contribute to a significant reduction in arterial stiffness $[30,70]$ by providing consistent feedback on progress [71-73]. In addition, digital health technologies that accurately estimate BP could potentially be used to titrate BP medications for patients with hypertension from the comfort of their homes [7,74]. In addition to these broader impacts, the knowledge gained from this study-especially when combined with the advent of low-profile, flexible electronics capable of robustly detecting physiological biosignals [75-78]—represents a significant step toward the unobtrusive monitoring of BP in ambulatory settings and health equity for persons in MUAs.

\section{Acknowledgments}

This work was funded in part by the National Institute of Health, National Institute of Biomedical Imaging and Bioengineering under grant 1U01EB018818-01, by the National Institute of Biomedical Imaging and Bioengineering Point-of-Care Technologies Research Network, Atlanta Center for Microsystems-Engineered Point-of-Care Technologies under grant 1U54EB027690, and by the National Center for Advancing Translational Sciences of the National Institutes of Health under award number UL1TR002378.

\section{Authors' Contributions}

VGG codeveloped the newer version of the hardware, performed human subject studies on the second cohort, analyzed the collected data, and coprepared the manuscript. AMC developed the older version of the hardware, codeveloped the newer version of the hardware, co-conducted human subject studies on the first cohort, and assisted in advising the analysis and editing of the manuscript. HJ co-conducted human subject studies on the first cohort and assisted in both human subject studies on the second cohort and editing of the manuscript. AVS assisted in both conducting human subject studies on the second cohort and editing of the manuscript. DC assisted in both participant recruitment for the second cohort and editing of the manuscript. LNJ assisted in advising the study, participant recruitment for the second cohort, and editing of the manuscript. OTI guided the study and coprepared the manuscript.

\section{Conflicts of Interest}

OTI is a cofounder of and scientific advisor at Cardiosense, Inc, and a scientific advisor at Physiowave, Inc. The funders had no role in the design of the study; in the collection, analyses, or interpretation of data; in the writing of the manuscript; or in the decision to publish the results.

\section{References}

1. Arrieta A, Woods JR, Qiao N, Jay SJ. Cost-benefit analysis of home blood pressure monitoring in hypertension diagnosis and treatment: an insurer perspective. Hypertension 2014 Oct;64(4):891-896. [doi: 10.1161/HYPERTENSIONAHA.114.03780] [Medline: 25024284]

2. Ghuman N, Campbell P, White WB. Role of ambulatory and home blood pressure recording in clinical practice. Curr Cardiol Rep 2009 Nov;11(6):414-421 [FREE Full text] [doi: 10.1007/s11886-009-0060-6] [Medline: 19863865]

3. Yarows SA, Staessen JA. How to use home blood pressure monitors in clinical practice. Am J Hypertens 2002 Jan;15(1 Pt 1):93-96. [doi: 10.1016/s0895-7061(01)02277-4] [Medline: 11824867 ]

4. Muntner P, Hardy ST, Fine LJ, Jaeger BC, Wozniak G, Levitan EB, et al. Trends in blood pressure control among US adults with hypertension, 1999-2000 to 2017-2018. J Am Med Assoc 2020 Sep 22;324(12):1190-1200. [doi: 10.1001/jama.2020.14545] [Medline: $\underline{32902588]}$ 
5. Zhou D, Xi B, Zhao M, Wang L, Veeranki SP. Uncontrolled hypertension increases risk of all-cause and cardiovascular disease mortality in US adults: the NHANES III Linked Mortality Study. Sci Rep 2018 Jun 20;8(1):9418 [FREE Full text] [doi: 10.1038/s41598-018-27377-2] [Medline: 29925884]

6. Doyle SK, Chang AM, Levy P, Rising KL. Achieving health equity in hypertension management through addressing the social determinants of health. Curr Hypertens Rep 2019 Jun 12;21(8):58. [doi: 10.1007/s11906-019-0962-7] [Medline: $\underline{31190099]}$

7. Inan OT, Tenaerts P, Prindiville SA, Reynolds HR, Dizon DS, Cooper-Arnold K, et al. Digitizing clinical trials. NPJ Digit Med 2020;3:101 [FREE Full text] [doi: 10.1038/s41746-020-0302-y] [Medline: $\underline{\text { 32821856] }}$

8. Sharma M, Barbosa K, Ho V, Griggs D, Ghirmai T, Krishnan S, et al. Cuff-less and continuous blood pressure monitoring: a methodological review. Technologies 2017 May 09;5(2):21. [doi: 10.3390/technologies5020021]

9. Arakawa T. Recent research and developing trends of wearable sensors for detecting blood pressure. Sensors (Basel) 2018 Aug 23;18(9):2772 [FREE Full text] [doi: 10.3390/s18092772] [Medline: 30142931]

10. Kario K, Shimbo D, Tomitani N, Kanegae H, Schwartz JE, Williams B. The first study comparing a wearable watch-type blood pressure monitor with a conventional ambulatory blood pressure monitor on in-office and out-of-office settings. J Clin Hypertens (Greenwich) 2020 Feb;22(2):135-141 [FREE Full text] [doi: 10.1111/jch.13799] [Medline: $\underline{31955505]}$

11. Bard DM, Joseph JI, van Helmond N. Cuff-less methods for blood pressure telemonitoring. Front Cardiovasc Med 2019;6:40 [FREE Full text] [doi: 10.3389/fcvm.2019.00040] [Medline: 31157236]

12. Mukkamala R, Hahn J, Inan OT, Mestha LK, Kim C, Töreyin H, et al. Toward ubiquitous blood pressure monitoring via pulse transit time: theory and practice. IEEE Trans Biomed Eng 2015 Aug;62(8):1879-1901 [FREE Full text] [doi: 10.1109/TBME.2015.2441951] [Medline: 26057530]

13. Etemadi M, Inan OT. Wearable ballistocardiogram and seismocardiogram systems for health and performance. J Appl Physiol (1985) 2018 Feb 01;124(2):452-461 [FREE Full text] [doi: 10.1152/japplphysiol.00298.2017] [Medline: 28798198]

14. Huynh TH, Jafari R, Chung W. Noninvasive cuffless blood pressure estimation using pulse transit time and impedance plethysmography. IEEE Trans Biomed Eng 2019 Apr;66(4):967-976. [doi: 10.1109/TBME.2018.2865751] [Medline: 30130167]

15. Bove AA, Santamore WP, Homko C, Kashem A, Cross R, McConnell TR, et al. Reducing cardiovascular disease risk in medically underserved urban and rural communities. Am Heart J 2011 Feb;161(2):351-359. [doi: 10.1016/j.ahj.2010.11.008] [Medline: 21315219]

16. Lincoln KD, Abdou CM, Lloyd D. Race and socioeconomic differences in obesity and depression among Black and non-Hispanic White Americans. J Health Care Poor Underserved 2014 Feb;25(1):257-275 [FREE Full text] [doi: 10.1353/hpu.2014.0038] [Medline: 24509025]

17. Saeed A, Dixon DL, Yang E. Racial disparities in hypertension prevalence and management: a crisis control? American College of Cardiology. 2020. URL: https://www.acc.org/latest-in-cardiology/articles/2020/04/06/08/53/ racial-disparities-in-hypertension-prevalence-and-management [accessed 2021-06-23]

18. Lackland DT. Racial differences in hypertension: implications for high blood pressure management. Am J Med Sci 2014 Aug;348(2):135-138 [FREE Full text] [doi: 10.1097/MAJ.0000000000000308] [Medline: 24983758]

19. Carek AM, Conant J, Joshi A, Kang H, Inan OT. SeismoWatch: wearable cuffless blood pressure monitoring using pulse transit time. Proc ACM Interact Mob Wearable Ubiquitous Technol 2017 Sep;1(3):40 [FREE Full text] [doi: 10.1145/3130905] [Medline: $\underline{\text { 30556049] }}$

20. Ganti VG, Carek A, Nevius BN, Heller J, Etemadi M, Inan O. Wearable cuff-less blood pressure estimation at home via pulse transit time. IEEE J Biomed Health Inform 2020 Sep 03;25(6):1926-1937. [doi: 10.1109/JBHI.2020.3021532] [Medline: $\underline{32881697]}$

21. The Practical Guide : identification, evaluation, and treatment of overweight and obesity in adults. NHLBI Obesity Education Initiative. 2000. URL: https://www.nhlbi.nih.gov/files/docs/guidelines/prctgd c.pdf [accessed 2021-06-23]

22. Parati G, Casadei R, Groppelli A, Di Rienzo M, Mancia G. Comparison of finger and intra-arterial blood pressure monitoring at rest and during laboratory testing. Hypertension 1989 Jun;13(6 Pt 1):647-655. [doi: 10.1161/01.hyp.13.6.647] [Medline: 2500393]

23. Wesseling KH, de Wit B, van der Hoeven GM, van Goudoever J, Settels JJ. Physiocal, calibrating finger vascular physiology for finapres. Homeostasis in Health and Disease 1995;36(2-3):67-82 [FREE Full text]

24. Chachula K, Lieb F, Hess F, Welter J, Graf N, Dullenkopf A. Non-invasive continuous blood pressure monitoring (ClearSight ${ }^{\mathrm{TM}}$ system) during shoulder surgery in the beach chair position: a prospective self-controlled study. BMC Anesthesiol 2020 Oct 24;20(1):271 [FREE Full text] [doi: 10.1186/s12871-020-01185-6] [Medline: 33099306]

25. Zhao Q, Bazzano LA, Cao J, Li J, Chen J, Huang J, et al. Reproducibility of blood pressure response to the cold pressor test: the GenSalt Study. Am J Epidemiol 2012 Oct 01;176 Suppl 7:91-98 [FREE Full text] [doi: 10.1093/aje/kws294] [Medline: 23035148]

26. Inan OT, Kovacs GT, Giovangrandi L. Evaluating the lower-body electromyogram signal acquired from the feet as a noise reference for standing ballistocardiogram measurements. IEEE Trans Inf Technol Biomed 2010 Sep;14(5):1188-1196. [doi: 10.1109/TITB.2010.2044185] [Medline: 20371416] 
27. Tseng S, Grant A, Durkin AJ. In vivo determination of skin near-infrared optical properties using diffuse optical spectroscopy. J Biomed Opt 2008;13(1):014016 [FREE Full text] [doi: 10.1117/1.2829772] [Medline: 18315374]

28. Yavarimanesh M, Chandrasekhar A, Hahn J, Mukkamala R. Commentary: Relation between blood pressure and pulse wave velocity for human arteries. Front Physiol 2019;10:1179 [FREE Full text] [doi: 10.3389/fphys.2019.01179] [Medline: 31572224]

29. 1708-2014 - IEEE Standard for Wearable Cuffless Blood Pressure Measuring Devices. Piscataway, New Jersey, United States: IEEE; 2014.

30. Wildman RP, Farhat GN, Patel AS, Mackey RH, Brockwell S, Thompson T, et al. Weight change is associated with change in arterial stiffness among healthy young adults. Hypertension 2005 Feb;45(2):187-192. [doi: 10.1161/01.HYP.0000152200.10578.5d] [Medline: 15596570]

31. Ahimastos AA, Formosa M, Dart AM, Kingwell BA. Gender differences in large artery stiffness pre- and post puberty. J Clin Endocrinol Metab 2003 Nov;88(11):5375-5380. [doi: 10.1210/jc.2003-030722] [Medline: 14602776]

32. Wu S, Jin C, Li S, Zheng X, Zhang X, Cui L, et al. Aging, arterial stiffness, and blood pressure association in Chinese adults. Hypertension 2019 Apr;73(4):893-899. [doi: 10.1161/HYPERTENSIONAHA.118.12396] [Medline: 30776974]

33. Alecu C, Gueguen R, Aubry C, Salvi P, Perret-Guillaume C, Ducrocq X, et al. Determinants of arterial stiffness in an apparently healthy population over 60 years. J Hum Hypertens 2006 Oct;20(10):749-756. [doi: 10.1038/sj.jhh.1002072] [Medline: 16855622]

34. Coutinho T. Arterial stiffness and its clinical implications in women. Can J Cardiol 2014 Jul;30(7):756-764. [doi: 10.1016/j.cjca.2014.03.020] [Medline: 24970788]

35. Schutte AE, Kruger R, Gafane-Matemane LF, Breet Y, Strauss-Kruger M, Cruickshank JK. Ethnicity and arterial stiffness. Arterioscler Thromb Vasc Biol 2020 May;40(5):1044-1054. [doi: 10.1161/ATVBAHA.120.313133] [Medline: 32237903]

36. Ding X, Zhang Y. Pulse transit time technique for cuffless unobtrusive blood pressure measurement: from theory to algorithm. Biomed Eng Lett 2019 Feb;9(1):37-52 [FREE Full text] [doi: 10.1007/s13534-019-00096-x] [Medline: 30956879]

37. Yang C, Tavassolian N. Pulse transit time measurement using seismocardiogram, photoplethysmogram, and acoustic recordings: evaluation and comparison. IEEE J Biomed Health Inform 2018 May;22(3):733-740. [doi: 10.1109/JBHI.2017.2696703] [Medline: 28436909]

38. MacDonald JR. Potential causes, mechanisms, and implications of post exercise hypotension. J Hum Hypertens 2002 Apr;16(4):225-236. [doi: 10.1038/sj.jhh.1001377] [Medline: 11967715]

39. Flint AC, Conell C, Ren X, Banki NM, Chan SL, Rao VA, et al. Effect of systolic and diastolic blood pressure on cardiovascular outcomes. N Engl J Med 2019 Jul 18;381(3):243-251. [doi: 10.1056/NEJMoa1803180] [Medline: 31314968]

40. Kannel WB, Gordon T, Schwartz MJ. Systolic versus diastolic blood pressure and risk of coronary heart disease. The Framingham study. Am J Cardiol 1971 Apr;27(4):335-346. [doi: 10.1016/0002-9149(71)90428-0] [Medline: 5572576]

41. Kaneko H, Itoh H, Yotsumoto H, Kiriyama H, Kamon T, Fujiu K, et al. Association of isolated diastolic hypertension based on the cutoff value in the 2017 American College of Cardiology/American Heart Association blood pressure guidelines with subsequent cardiovascular events in the general population. J Am Heart Assoc 2020 Oct 20;9(19):e017963 [FREE Full text] [doi: 10.1161/JAHA.120.017963] [Medline: $\underline{\text { 32993440] }}$

42. Domanski MJ, Davis BR, Pfeffer MA, Kastantin M, Mitchell GF. Isolated systolic hypertension : prognostic information provided by pulse pressure. Hypertension 1999 Sep;34(3):375-380. [doi: 10.1161/01.hyp.34.3.375] [Medline: 10489379]

43. Kanegae H, Oikawa T, Okawara Y, Hoshide S, Kario K. Which blood pressure measurement, systolic or diastolic, better predicts future hypertension in normotensive young adults? J Clin Hypertens (Greenwich) 2017 Jun;19(6):603-610 [FREE Full text] [doi: 10.1111/jch.13015] [Medline: 28444926]

44. Franklin SS, Larson MG, Khan SA, Wong ND, Leip EP, Kannel WB, et al. Does the relation of blood pressure to coronary heart disease risk change with aging? The Framingham Heart Study. Circulation 2001 Mar 06;103(9):1245-1249. [doi: 10.1161/01.cir.103.9.1245] [Medline: 11238268]

45. Taylor BC, Wilt TJ, Welch HG. Impact of diastolic and systolic blood pressure on mortality: implications for the definition of "normal". J Gen Intern Med 2011 Jul;26(7):685-690 [FREE Full text] [doi: 10.1007/s11606-011-1660-6] [Medline: 21404131]

46. World Health Organization. Global Action Plan for the Prevention and Control of NCDs 2013-2020. Geneva: World Health Organization; 2013:1-103.

47. Convertino VA, Schauer SG, Weitzel EK, Cardin S, Stackle ME, Talley MJ, et al. Wearable sensors incorporating compensatory reserve measurement for advancing physiological monitoring in critically injured trauma patients. Sensors (Basel) 2020 Nov 10;20(22):6413 [FREE Full text] [doi: 10.3390/s20226413] [Medline: 33182638]

48. Bent B, Goldstein BA, Kibbe WA, Dunn JP. Investigating sources of inaccuracy in wearable optical heart rate sensors. NPJ Digit Med 2020;3:18 [FREE Full text] [doi: 10.1038/s41746-020-0226-6] [Medline: 32047863]

49. Tseng S, Bargo P, Durkin A, Kollias N. Chromophore concentrations, absorption and scattering properties of human skin in-vivo. Opt Express 2009 Aug 17;17(17):14599-14617 [FREE Full text] [doi: 10.1364/oe.17.014599] [Medline: 19687939]

50. Allen J. Photoplethysmography and its application in clinical physiological measurement. Physiol Meas 2007 Mar;28(3):1-39. [doi: 10.1088/0967-3334/28/3/R01] [Medline: 17322588] 
51. El-Hajj C, Kyriacou P. A review of machine learning techniques in photoplethysmography for the non-invasive cuff-less measurement of blood pressure. Biomed Signal Process Control 2020 Apr;58:101870. [doi: 10.1016/j.bspc.2020.101870]

52. Wang L, Zhou W, Xing Y, Zhou X. A novel neural network model for blood pressure estimation using photoplethesmography without electrocardiogram. J Healthc Eng 2018;2018:7804243 [FREE Full text] [doi: 10.1155/2018/7804243] [Medline: 29707186]

53. He J, Muntner P, Chen J, Roccella EJ, Streiffer RH, Whelton PK. Factors associated with hypertension control in the general population of the United States. Arch Intern Med 2002 May 13;162(9):1051-1058. [doi: 10.1001/archinte.162.9.1051] [Medline: 11996617$]$

54. Shea S, Misra D, Ehrlich MH, Field L, Francis CK. Predisposing factors for severe, uncontrolled hypertension in an inner-city minority population. N Engl J Med 1992 Sep 10;327(11):776-781. [doi: 10.1056/NEJM199209103271107] [Medline: 1501654]

55. Komine H, Asai Y, Yokoi T, Yoshizawa M. Non-invasive assessment of arterial stiffness using oscillometric blood pressure measurement. Biomed Eng Online 2012 Feb 10;11:6 [FREE Full text] [doi: 10.1186/1475-925X-11-6] [Medline: 22325084]

56. Hughes DJ, Babbs CF, Geddes LA, Bourland JD. Measurements of Young's modulus of elasticity of the canine aorta with ultrasound. Ultrason Imaging 1979 Oct;1(4):356-367. [doi: 10.1177/016173467900100406] [Medline: 575833 ]

57. Hall JE, do Carmo JM, da Silva AA, Wang Z, Hall ME. Obesity-induced hypertension: interaction of neurohumoral and renal mechanisms. Circ Res 2015 Mar 13;116(6):991-1006 [FREE Full text] [doi: 10.1161/CIRCRESAHA.116.305697] [Medline: 25767285]

58. AlGhatrif M, Strait JB, Morrell CH, Canepa M, Wright J, Elango P, et al. Longitudinal trajectories of arterial stiffness and the role of blood pressure: the Baltimore Longitudinal Study of Aging. Hypertension 2013 Nov;62(5):934-941 [FREE Full text] [doi: 10.1161/HYPERTENSIONAHA.113.01445] [Medline: 24001897]

59. Sinha MD, Gilg JA, Kerecuk L, Reid CJ, British Association for Paediatric Nephrology. Progression to hypertension in non-hypertensive children following renal transplantation. Nephrol Dial Transplant 2012 Jul;27(7):2990-2996. [doi: 10.1093/ndt/gfr784] [Medline: 22287656]

60. Scuteri A, Orru' M, Morrell CH, Tarasov K, Schlessinger D, Uda M, et al. Associations of large artery structure and function with adiposity: effects of age, gender, and hypertension. The SardiNIA Study. Atherosclerosis 2012 Mar;221(1):189-197 [FREE Full text] [doi: 10.1016/j.atherosclerosis.2011.11.045] [Medline: 22222417]

61. Leggio M, Lombardi M, Caldarone E, Severi P, D'Emidio S, Armeni M, et al. The relationship between obesity and hypertension: an updated comprehensive overview on vicious twins. Hypertens Res 2017 Dec;40(12):947-963. [doi: 10.1038/hr.2017.75] [Medline: 28978986]

62. Najjar SS, Scuteri A, Shetty V, Wright JG, Muller DC, Fleg JL, et al. Pulse wave velocity is an independent predictor of the longitudinal increase in systolic blood pressure and of incident hypertension in the Baltimore Longitudinal Study of Aging. J Am Coll Cardiol 2008 Apr 08;51(14):1377-1383 [FREE Full text] [doi: 10.1016/j.jacc.2007.10.065] [Medline: 18387440]

63. Philips JC, Marchand M, Scheen AJ. Squatting, a posture test for studying cardiovascular autonomic neuropathy in diabetes. Diabetes Metab 2011 Dec;37(6):489-496. [doi: 10.1016/j.diabet.2011.09.004] [Medline: 22071282]

64. Rossberg F, Penaz J. Initial cardiovascular response on change of posture from squatting to standing. Eur J Appl Physiol Occup Physiol 1988;57(1):93-97. [doi: 10.1007/BF00691245] [Medline: 3342800]

65. Barnes SC, Ball N, Haunton VJ, Robinson TG, Panerai RB. The cerebrocardiovascular response to periodic squat-stand maneuvers in healthy subjects: a time-domain analysis. Am J Physiol Heart Circ Physiol 2017 Dec 01;313(6):1240-1248 [FREE Full text] [doi: 10.1152/ajpheart.00331.2017] [Medline: 28887332]

66. Zia J, Kimball J, Hersek S, Inan OT. Modeling consistent dynamics of cardiogenic vibrations in low-dimensional subspace. IEEE J Biomed Health Inform 2020 Jul;24(7):1887-1898. [doi: 10.1109/JBHI.2020.2980979] [Medline: 32175880]

67. Zia J, Kimball J, Inan O. Localizing placement of cardiomechanical sensors during dynamic periods via template matching. In: Proceedings of the 42nd Annual International Conference of the IEEE Engineering in Medicine \& Biology Society (EMBC). 2020 Presented at: 42nd Annual International Conference of the IEEE Engineering in Medicine \& Biology Society (EMBC); July 20-24, 2020; Montreal, QC, Canada p. 473-476. [doi: 10.1109/EMBC44109.2020.9176732]

68. Guanqun Z, Da X, Olivier N, Mukkamala R. Pulse arrival time is not an adequate surrogate for pulse transit time in terms of tracking diastolic pressure. In: Proceedings of the Annual International Conference of the IEEE Engineering in Medicine and Biology Society. 2011 Presented at: Annual International Conference of the IEEE Engineering in Medicine and Biology Society; Aug. 30 - Sept. 3, 2011; Boston, MA, USA p. 6462-6464. [doi: 10.1109/IEMBS.2011.6091595]

69. Shandhi MM, Semiz B, Hersek S, Goller N, Ayazi F, Inan OT. Performance analysis of gyroscope and accelerometer sensors for seismocardiography-based wearable pre-ejection period estimation. IEEE J Biomed Health Inform 2019 Nov;23(6):2365-2374 [FREE Full text] [doi: 10.1109/JBHI.2019.2895775] [Medline: 30703050]

70. De Ciuceis C, Porteri E, Rizzoni D, Corbellini C, La Boria E, Boari GE, et al. Effects of weight loss on structural and functional alterations of subcutaneous small arteries in obese patients. Hypertension 2011 Jul;58(1):29-36. [doi: 10.1161/HYPERTENSIONAHA.111.171082] [Medline: 21555677] 
71. Ryan J, Edney S, Maher C. Anxious or empowered? A cross-sectional study exploring how wearable activity trackers make their owners feel. BMC Psychol 2019 Jul 03;7(1):42 [FREE Full text] [doi: 10.1186/s40359-019-0315-y] [Medline: 31269972]

72. Bove LA. Increasing patient engagement through the use of wearable technology. J Nurse Pract 2019 Sep;15(8):535-539. [doi: 10.1016/j.nurpra.2019.03.018]

73. Greiwe J, Nyenhuis SM. Wearable technology and how this can be implemented into clinical practice. Curr Allergy Asthma Rep 2020 Jun 06;20(8):36 [FREE Full text] [doi: 10.1007/s11882-020-00927-3] [Medline: 32506184]

74. Stergiou GS, Baibas NM, Gantzarou AP, Skeva II, Kalkana CB, Roussias LG, et al. Reproducibility of home, ambulatory, and clinic blood pressure: implications for the design of trials for the assessment of antihypertensive drug efficacy. Am J Hypertens 2002 Feb;15(2 Pt 1):101-104. [doi: 10.1016/s0895-7061(01)02324-x] [Medline: 11863243]

75. Lee K, Ni X, Lee JY, Arafa H, Pe DJ, Xu S, et al. Mechano-acoustic sensing of physiological processes and body motions via a soft wireless device placed at the suprasternal notch. Nat Biomed Eng 2020 Feb;4(2):148-158 [FREE Full text] [doi: 10.1038/s41551-019-0480-6] [Medline: 31768002]

76. Boutry CM, Beker L, Kaizawa Y, Vassos C, Tran H, Hinckley AC, et al. Biodegradable and flexible arterial-pulse sensor for the wireless monitoring of blood flow. Nat Biomed Eng 2019 Jan;3(1):47-57. [doi: 10.1038/s41551-018-0336-5] [Medline: 30932072]

77. Wang C, Li X, Hu H, Zhang L, Huang Z, Lin M, et al. Monitoring of the central blood pressure waveform via a conformal ultrasonic device. Nat Biomed Eng 2018 Sep;2(9):687-695 [FREE Full text] [doi: 10.1038/s41551-018-0287-x] [Medline: 30906648]

78. Ha T, Tran J, Liu S, Jang H, Jeong H, Mitbander R, et al. A chest-laminated ultrathin and stretchable e-tattoo for the measurement of electrocardiogram, seismocardiogram, and cardiac time intervals. Adv Sci (Weinh) 2019 Jul 17;6(14):1900290 [FREE Full text] [doi: 10.1002/advs.201900290] [Medline: 31380208]

\author{
Abbreviations \\ ABP: arterial blood pressure \\ AFE: analog front end \\ AO: aortic valve opening \\ BP: blood pressure \\ BPF: bandpass filter \\ DBP: diastolic blood pressure \\ ECG: electrocardiogram \\ IEEE: Institute for Electronics and Electrical Engineers \\ IR: infrared \\ LED: light-emitting diode \\ MAD: mean absolute difference \\ MAP: mean arterial pressure \\ ML: machine learning \\ MUA: medically underserved area \\ PCC: Pearson correlation coefficient \\ PEP: pre-ejection period \\ PPG: photoplethysmogram \\ PTT: pulse transit time \\ PWV: pulse wave velocity \\ RMSE: root mean square error \\ SBP: systolic blood pressure \\ SCG: seismocardiogram \\ SNR: signal-to-noise ratio
}


Edited by L Buis; submitted 26.01.21; peer-reviewed by J Rogers, S Omboni; comments to author 02.02.21; revised version received 10.02.21; accepted 10.05.21; published 02.08.21

Please cite as:

Ganti V, Carek AM, Jung H, Srivatsa AV, Cherry D, Johnson LN, Inan OT

Enabling Wearable Pulse Transit Time-Based Blood Pressure Estimation for Medically Underserved Areas and Health Equity: Comprehensive Evaluation Study

JMIR Mhealth Uhealth 2021;9(8):e27466

URL: https://mhealth.jmir.org/2021/8/e27466

doi: $10.2196 / 27466$

PMID: 34338646

(C) Venu Ganti, Andrew M Carek, Hewon Jung, Adith V Srivatsa, Deborah Cherry, Levather Neicey Johnson, Omer T Inan. Originally published in JMIR mHealth and uHealth (https://mhealth.jmir.org), 02.08.2021. This is an open-access article distributed under the terms of the Creative Commons Attribution License (https://creativecommons.org/licenses/by/4.0/), which permits unrestricted use, distribution, and reproduction in any medium, provided the original work, first published in JMIR mHealth and uHealth, is properly cited. The complete bibliographic information, a link to the original publication on https://mhealth.jmir.org/, as well as this copyright and license information must be included. 